www.jmscr.igmpublication.org

\title{
Association between Smoking and Silent Peptic Ulcer Disease in the General Population of Kashmir
}

\author{
Authors \\ Prince Muzafer Wani ${ }^{1}$, Raheeb Ahmad Shah ${ }^{2}$, Sajad Ahmad Para ${ }^{3}$, \\ Parvez Ahmad Bhat ${ }^{4}$, \\ ${ }^{1}$ Senior Resident, Department of General Surgery, SKIMS. \\ ${ }^{2}$ Medical Officer, Department of General Surgery, NRHM \\ ${ }^{3}$ Senior Resident, Department of Urology, Fortis \\ ${ }^{4}$ Senior Resident, Department of General Ophthalmology, SKIMS. \\ Corresponding Author \\ Dr. Prince Muzafer \\ Senior Resident, Department of General Surgery, SKIMS Soura Srinagar \\ Email: princewani46@gmail.com,Cell: +91-9906880431
}

\section{ABSTRACT}

Objectives: To assess the occurrence of silent peptic ulcer disease (PUD) in patients who smoke and try to define the relationship between the two.

Methods: The study was carried out between $10^{\text {th }}$ January 2014 to $28^{\text {th }}$ November 2014 in the general surgical department of SMHS hospital in Srinagar, Kashmir. The patients with Smoking exposure of at least one pack-year, and current smoker, Negative serology for H. Pylori, No (or occasional) history of NSAID intakel alcohol consumption were included in the study. The end point of the study was one year follow-up.

Results: The evidence of peptic ulcer disease on endoscopy was found in 23 subjects, 19 of these occurred in male subjects while 4 were in female subject.

Conclusion: Based on our study, we conclude that silent peptic ulcer disease is fairly common in smokers than previously thought, and the risk of acquiring it increases with increase in smoking exposure. We conclude that upper gastrointestinal endoscopy should be a routine at 10 pack-years of exposure irrespective of age. Also, PPI/H $\mathrm{H}_{2}$ blockers should be considered in smokers irrespective of symptoms.

Keywords: Kashmir, peptic ulcer, smoking, H. pylori, endoscopy.

\section{INTRODUCTION}

Smoking is a common social problem world over, and the population of subcontinent is no exception to it. In Kashmir, we have seen it in about $60 \%$ of the total OPD patients visiting our tertiary care hospital. Among different forms of smoking, filtered cigarettes account for roughly $70 \%$, while hookah accounts for about $24 \%$ of forms of smoking. The health impacts of smoking are vast with notables being lung cancer, COPD, peptic ulceration, oesophageal cancers etc.

Smoking seems to be a risk factor of major importance for ulcerperforation.A study from Norway showed a strong association between 
ulcer perforation and smoking ${ }^{1}$. One study also shows that it may be a stronger factor than $\mathrm{H}$. Pylori in causation of PUD in certain populations $^{2}$. However not all peptic ulcer diseases are symptomatic. Asymptomatic ulcers are common in patients who take aspirin and other NSAIDS. They are also common in patients with H. Pylori infestation ${ }^{3}$. Smoking also plays an important role in the occurrence of silent peptic ulcer disease.

In this study, we will assess the occurrence of silent peptic ulcer disease (PUD) in patients who smoke and try to define the relationship between the two.

\section{MATERTIALS AND METHODS}

The study was carried out between $10^{\text {th }}$ jan.2014 to $28^{\text {th }}$ November 2014 in the general surgical department of a tertiary care hospital in Srinagar, Kashmir. A total of 134 endoscopies were performed during this period for the purpose of this study.

The selection criteria of subjects for the study were:

- Age $\geq 45$ years

- No history of previous peptic ulcer disease/ PPI (or $\mathrm{H}_{2}$ antagonist) use.

- No previous endoscopies
- Smoking exposure of atleast one packyear, and current smoker.

- Both sexes

- Negative serology for H.Pylori

- No (or occasional) history of NSAID intake/ alcohol consumption.

- No alcohol consumption/ steroid use.

In Kashmir, screening endoscopies are fairly common from 45 years of age; hence this age group was chosen for this study to increase "yield". A thorough history was taken from each participant of the study to exclude any peptic ulcer disease in the past. Similar history was taken to rule out any aetiologies of PUD like NSAIDs, Alcohol, H.Pylori, stressful lifestyles etc. None of the study subjects in the group has had any previous upper GI endoscopies.

The smoking history was quantified in terms of pack-years. Because in India cigarettes are dispensed in a pack of 10, unlike in western countries where its 20 per pack, therefore, each Indian brand of cigarettes pack was considered $1 / 2$ pack. This was done for the standardisation of results to be obtained thereof. None of the study subjects in our study consumed foreign brands or smoked hookah. An informed consent was taken from each participant of the study.

The demographic features of the study population are as shown in table 1 .

\begin{tabular}{|l|l|l|}
\hline & male & female \\
\hline$n$ & 90 & 44 \\
\hline age & $52.1 \pm 5.25$ & $50.56 \pm 4.80$ \\
\hline BMI & $22.6 \pm 2.49$ & $25.11 \pm 2.97$ \\
\hline smoking & $58(64.4 \%)$ & $8(18.18 \%)$ \\
\hline
\end{tabular}

The low incidence of smoking trends in women subjects above can be attributed to the fact that in conservative societies smoking by women is considered a taboo, and hence discouraged.

\section{RESULTS}

The evidence of peptic ulcer diseaseon endoscopy was found in 23 subjects. 19 of these occurred in male subjects while 4 was in female subject. Most of these lesions were duodenal erosions (fig. 1). 


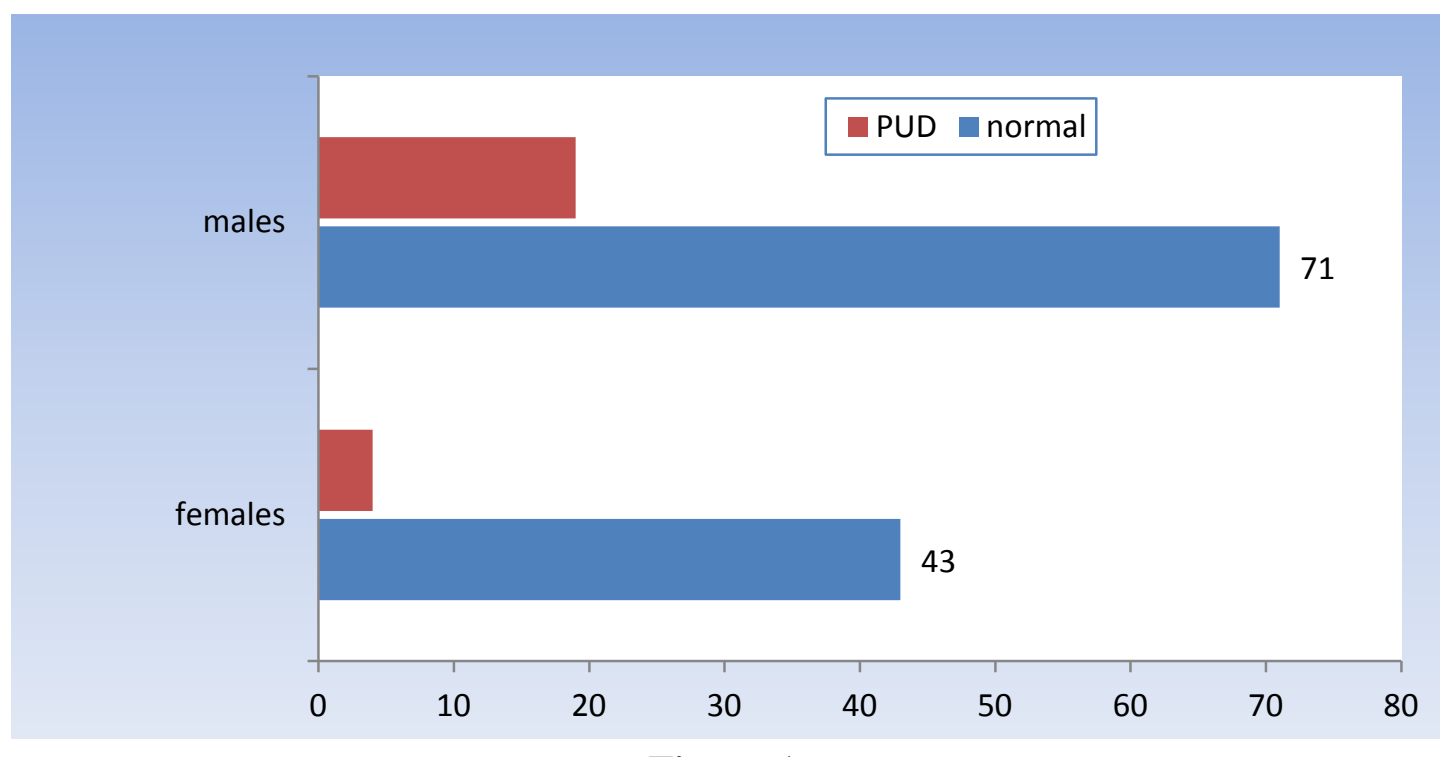

Figure 1

Table 2 and fig. 2depicts the relationship between smoking and PUD.

\begin{tabular}{|llllll|}
\hline \multirow{2}{*}{ smoker } & & & PUD & No PUD & $\begin{array}{c}* p- \\
\text { value }\end{array}$ \\
& Male & 58 & 16 & 42 & $<0.05$ \\
\cline { 2 - 6 } & Female & 8 & 3 & 5 & \\
\hline No smoking & Male & 32 & 3 & 29 & \\
\hline & Female & 36 & 1 & 35 & \\
\cline { 2 - 6 } & & & & & \\
\end{tabular}

Table 2 (* Fischer's exact)

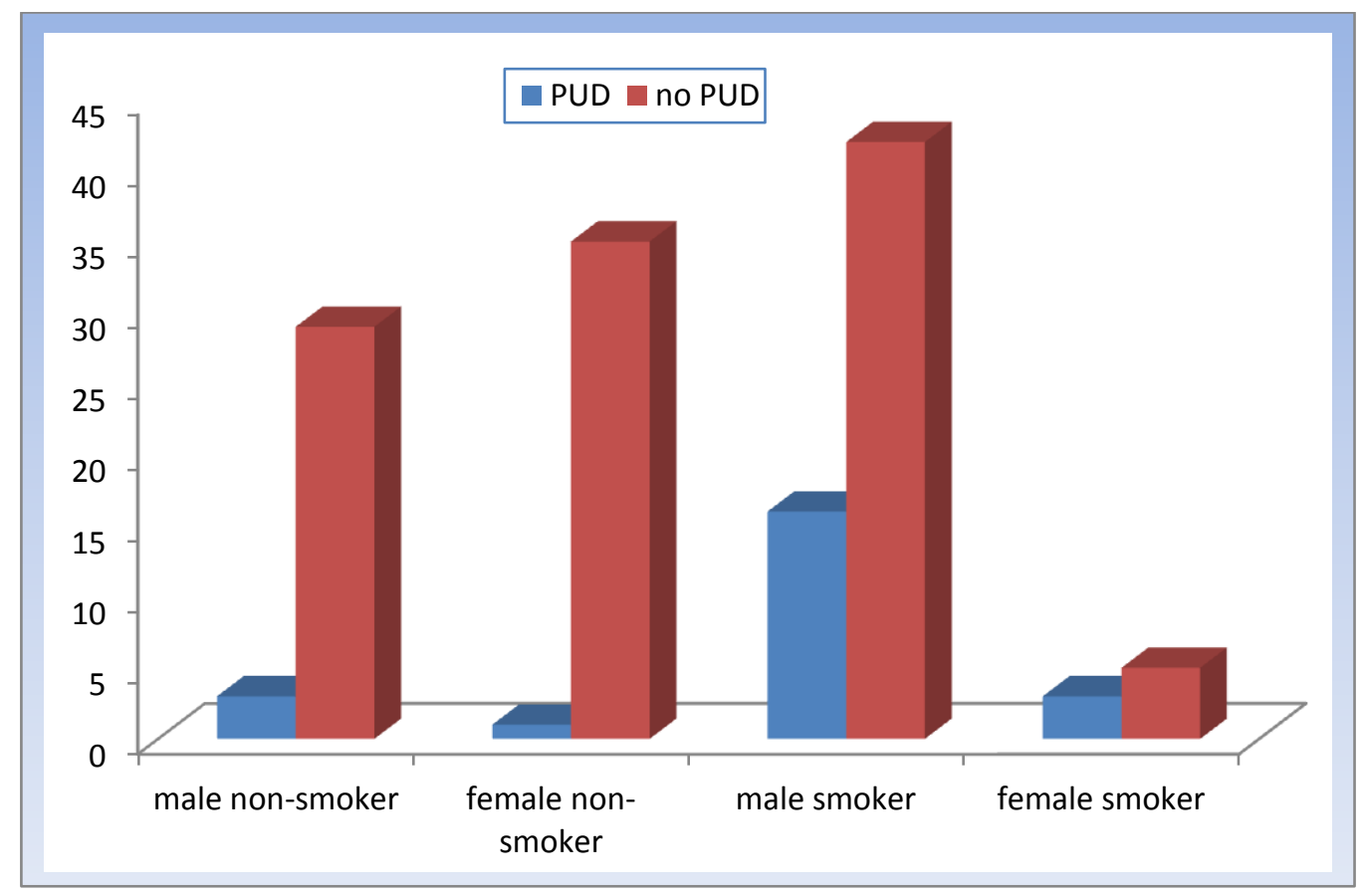

Figure 2 
Smoking exposure was further stratified in various groups and the data extrapolated as shown below (table 3):

\begin{tabular}{llll}
\hline Quantity of smoking & PUD & No. of smokers & RR \\
\hline$<$ 2 pack-years & 02 & 10 & 3.4 \\
\hline 2-5 pack-years & 02 & 24 & 1.41 \\
\hline 5-10 pack- years & 04 & 12 & 5.66 \\
\hline$>$ 10 pack years & 11 & 20 & 9.35 \\
\hline TOTAL & 19 & 66 & \\
\hline
\end{tabular}

\section{Table 3}

As calculated from the table above, we can see that the relative risk (RR)of developing silent PUD at $>10$ pack-years is 9.35 ( 9.4). Also, relative risk at $>5$ pack-years is 5.66 .
Theserelative rates are calculated with respect to non-smoker study group (i.e. 4 silent PUD in a group of 68 non-smokers). This is further illustrated graphically in fig.3.

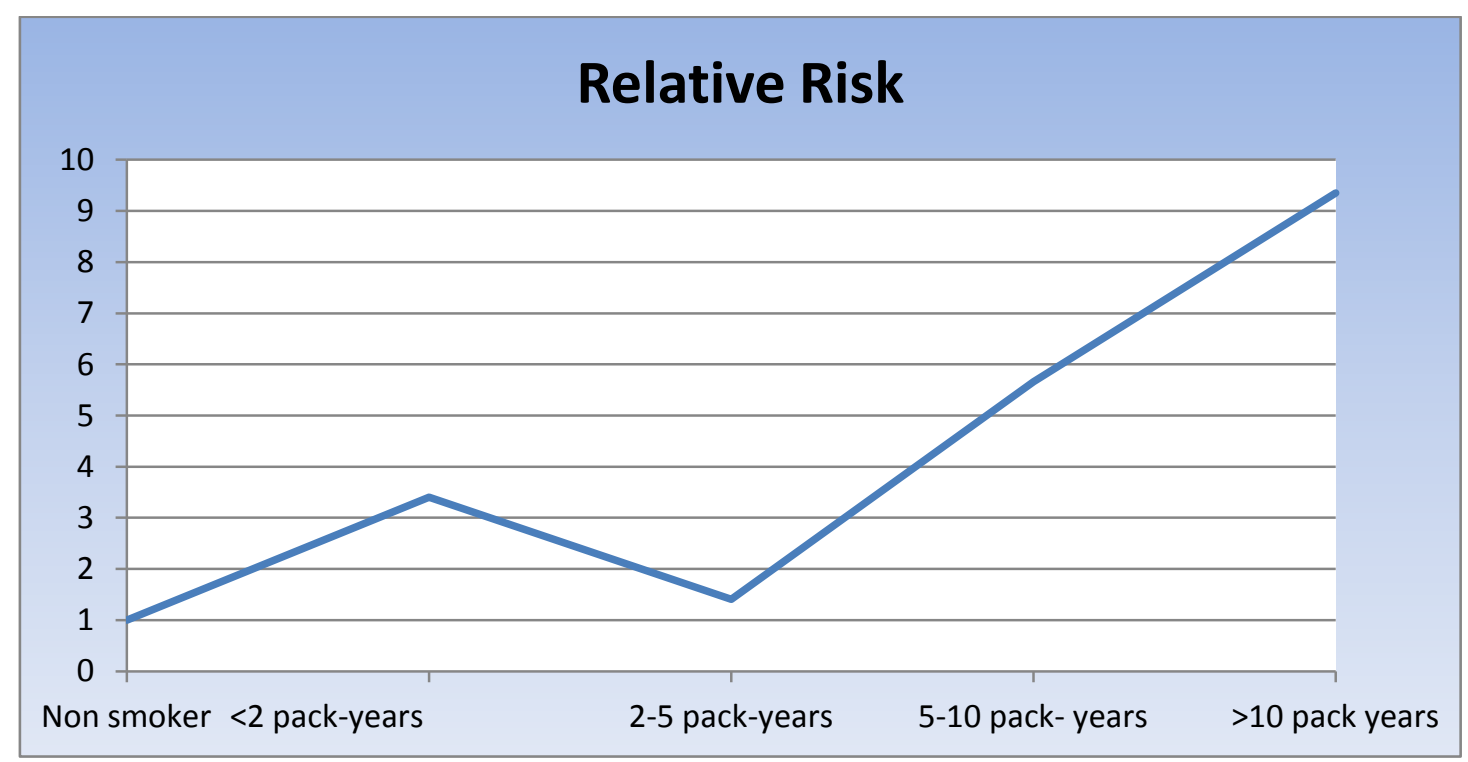

Fig. 3

\section{DISCUSSION}

Peptic ulcer disease is fairly common worldwide with fair number of patients in subcontinent. As we all know that the various risk factors for developing PUD are H. Pylori infection, NSAIDS, Alcohol, Smoking, Steroids etc. Although, the association between coffee drinking and PUD iscontroversial $^{4}$. Smoking is one of the important factors in the causation of PUD. In factSmoking seems to be a risk factor for complicated PUD like perforation and gastric outlet obstruction ${ }^{5,6}$.
Although various factors of peptic ulcer causation exist together, we tried to exclude them to in this study to the best of our ability. The main idea was to study smoking in isolation to other risk factors and determine its exact role as a causative agent in silent PUD. Fortunately enough for us, alcohol consumption is a very minor trend in Kashmiri population; and none of our subjects in both the groups had any history of alcohol intake - past or present. As regards NSAIDS, we excluded all the patients with a regular history of NSAIDS intake 
and only included those patients who had no history of exposure to NSAIDS (oral or topical); or at the most an occasional exposure to cox-2 NSAIDS (defined as once in 4-6 months).

H. Pylori was excluded with commercially available serological kits available. Diet plays a role in the development of gastritis, especially in winter months when fresh fruits and fresh vegetables are not available ${ }^{7}$. In addition, smoking of small fresh water fish, called "pher" in Kashmiri language, is a winter delicacy in Kashmir. Care was taken to include only those subjects who had either low or no exposure to "pher". Besides, the subjects were allotted to each group keeping all the attributes in mind so as to minimise investigator and observer bias.This study assumed a combined outcome of gastric and duodenal ulcers, gastric and duodenal erosions, all detected by endoscopy in the absence of any symptoms. The results were obtained and subjected to various statistical tests.

\section{CONCLUSION}

Based on our study, we believe that silent peptic ulcer disease is fairly common in smokers than previously thought, and the risk of acquiring it increases with increase in smoking exposure. We feel that upper gastrointestinal endoscopy should be a routine at 10 pack-years of exposure irrespective of age. Also, $\mathrm{PPI} / \mathrm{H}_{2}$ blockers should be considered in smokers irrespective of symptoms.

\section{REFERENCES}

1. Svanes C, Soreide JA, Skarstein A, Svanes BT, Svanes K, Soreide O. Smoking and ulcer perforation. Gut 1997; 41: 177.

2. Anderson IB, Jorgensen T, Bonnevie O, et al. Smoking and alcohol intake as risk factors for bleeding and perforated peptic ulcers: a population based cohort study. Epidemiology 2000; 11: 434-9.
3. Bjorkman, David J. How common is silent peptic ulcer disease? Journal watch. Gastroenterology 2004; ISSN 15271579.

4. Suadicani P, Hein HO, Gyntelberg F. Genetic and lifestyle determinants of peptic ulcer. A study of 3387 men aged 54 to 74 years: the Copenhagen male study. Scand J Gastrroenteral 1999; 34: 12-17.

5. Reinbach DH, Cruickshank G, McColl KEL. Acute perforated duodenal ulcer is not associated with Helicobacter pylori infection. Gut 1993; 34: 1344.

6. Smedley F, Hickish T, Taube M, Yale C, Leach R, Wastell C. Perforated duodenal ulcer and cigarette smoking. J. R. Soc. Med. 1998; 81: 92.

7. Graham DY, Asaka M. Eradication of gastric cancer and more efficient gastric cancer surveillance in Japan: Two peas in a pod. J Gastroenterol 2010; 45: 1-8. 